This item was submitted to Loughborough's Research Repository by the author.

Items in Figshare are protected by copyright, with all rights reserved, unless otherwise indicated.

\title{
Technology assisted risk assessment in homecare
}

\section{PLEASE CITE THE PUBLISHED VERSION}

http://itekcmsonline.com/rps2prod/esrel2019/e-proceedings/html/0910.xml

\section{PUBLISHER}

Research Publishing Services, Singapore

VERSION

AM (Accepted Manuscript)

\section{LICENCE}

All Rights Reserved

REPOSITORY RECORD

Power, Luke, Sarah Dunnett, and Lisa Jackson. 2019. "Technology Assisted Risk Assessment in Homecare". figshare. https://hdl.handle.net/2134/38238. 


\title{
Technology Assisted Risk Assessment in Homecare
}

\author{
Luke Power \\ Loughborough University, Aeronautical and Automotive Engineering, United Kingdom. E-mail: \\ l.power@lboro.ac.uk
}

\author{
Sarah Dunnett \\ Loughborough University, Aeronautical and Automotive Engineering, United Kingdom. E-mail: \\ S.J.Dunnett@lboro.ac.uk \\ Lisa Jackson \\ Loughborough University, Aeronautical and Automotive Engineering, United Kingdom. E-mail: \\ L.M.Jackson@lboro.ac.uk
}

\begin{abstract}
The home is a key environment for geriatric care. Research has demonstrated patients discharged to their homes are at a high risk of readmission of transitioning to homecare. The ability for care providers to predict and mitigate risk is limited in this environment. Significant observational requirements hinder continued diagnosis which limits timely interventions before a readmission event. Technology is used to resolve this issue and provide enhanced risk assessments by gathering data, however these technologies present a wide variety of challenges including barriers to use and ethical considerations which hinder an effective solution. This paper seeks to examine the necessary observations homecare providers require to form effective risk assessments and interventions in the home. This is achieved by remote monitoring through Bluetooth low energy (BLE) sensors for the common causes of hospital readmissions including observed difficulties in activities of daily living (ADL), heart rate fluctuations and falls. Risk is assessed by examining these factors as events to deduce behaviour or apparent reduction in capacity to function in daily life. Results obtained when using BLE sensors, heart rate monitors and fall detectors show it is possible to observe and record events of interest to health care providers in the provision of geriatric homecare. Patterns within sensor data could be used in the home environment to form an effective patient risk analysis given remote monitoring access to a patient and prescribed care plan to evaluate outcomes and possibility of readmission. Further experiments will test and validate the risk assessment analysis formed in this paper.
\end{abstract}

Keywords: Healthcare, Sensors, Homecare, Monitoring, Pattern Detection, Assistive Diagnosis.

\section{Risk Assessment in the Home}

With the improvements in living conditions and medical science the elderly population continues to expand which necessitates a greater focus on this group's healthcare. National healthcare systems have come under strain to provide elderly care outside the hospital due to over-demand and growing evidence to suggest the home as the preferred environment to provide care (Hesselink et al., 2012). As patient care transfers to the uncontrolled environment of the home, significant focus must be placed on the patients short and long-term susceptibility to risk. Risk assessment (RA) frameworks are in active use within elderly homecare for this purpose, among them are CAFA (Common Assessment Framework for Adults), ADL (Activities of Daily Living) and NICE
(National Institute for Health and Care Guidance). Each address common care requirements elderly patients have by observing events associated with physical and mental wellbeing risk (Soldato et al., 2007). Healthcare professionals provide observation over short and long periods of time to evaluate the patient's ability to perform tasks which indicate wellbeing and establish potential risks. Demand for care professionals however such as the community nurse cannot be currently met and will only worsen in the future (CarersUK, 2015). The diminishing workforce makes the effective delivery of RA frameworks difficult due to the reliance on observations being recorded (CarersUK, 2015). This presents unacceptable availability of services and introduces the possibility of negative risk to the patient who benefit from effective risk and health assessment (Caradoc-

Proceedings of the 29th European Safety and Reliability Conference.

Edited by Michael Beer and Enrico Zio

Copyright $(02019$ by ESREL2019 Organizers. Published by Research Publishing, Singapore

ISBN: 981-973-0000-00-0 :: doi: 10.3850/981-973-0000-00-0 esrel2019-paper 
Davies et al 1989). The emerging field of health monitoring technologies seeks to address the problem by automating the observation process.

\section{Monitoring and Assessment Using BLE}

Research has substantiated the efficacy of remote sensor technologies for observing home patients over short and long-term periods of time, this led to successful care alternations based on these observations (Wade et al., 2012). The focus however is often on non-communicable diseases (NCD) such as chronic heart failure and diabetes, RA frameworks in contrast require a broader range of observations such as movement, sedentary behaviour, falls detection and heart rate (HR) (Kenneth et al, 2003). This provides a new challenge to homecare technology as assessment frameworks such as ADL rely on patient behaviour observation (Feil, 2016). The purpose of the research described here is to investigate the ability of BLE devices to monitor patients while providing evaluations of risk using remote lifestyle observations. As BLE devices use approximate positioning for monitoring they offer the ability to obtain patient location, movements and activities within a home while technologies such as cameras and GSP have limitations (Power et al, 2018). RA is completed using a combination of the ADL and NICE assessment frameworks a list of events can be derived which are associated with unique activities performed by patients in their homes. By classifying sensor observed events, the effectiveness of BLE monitoring for RA can examined.

\section{Methodology}

BLE as a remote indoor positioning system (IPS) can be used to gather activity patterns of home patients which requires the classification of these observations in home environments, ADL details a set of conditions such as transferring, eating and sedentary levels as a framework to assess home patient health and independence. Interactions observed using IPS should align with ADL conditions for physical and mental wellbeing (Katz, 1983). Movement would be probable when BLE beacons observe transfer between rooms, attempts to gain nourishment could be interpreted through kitchen proximity and OOI interactions. Three event types were chosen to fulfil the observational requirements of RA frameworks using BLE monitoring. These events contain the activity which appear most frequently in all the RA frameworks outlined (George et al, 2004). These events are recorded using stationary BLE devices emitting radio signals which are intercepted by a patient worn wrist receiver. Table 1 shows observable data of location, activity and heartrate which is classified into event categories as patients carry out daily tasks during monitoring. Captured data is classified into events corresponding to the risk with which they are associated, this classification is informed from RA frameworks (George et al, 2004).

Table 1: Risk Event Classification

\begin{tabular}{|c|c|c|c|}
\hline Event & $\begin{array}{l}\text { Descriptio } \\
\mathrm{n}\end{array}$ & $\begin{array}{l}\text { Identificatio } \\
\mathrm{n}\end{array}$ & $\begin{array}{l}\text { Risk } \\
\text { Assessed }\end{array}$ \\
\hline Motion & $\begin{array}{l}\text { Variance } \\
\text { in position, } \\
\text { proximity } \\
\text { to } \\
\text { transferrin } \\
\text { g targets } \\
\text { such as } \\
\text { chairs and } \\
\text { beds }\end{array}$ & $\begin{array}{l}\text { Range from } \\
\text { BLE device } \\
\text { changes } \\
\text { from Close } \\
\text { to Near to } \\
\text { Far. HR } \\
\text { elevation. } \\
\text { Force } \\
\text { Detection }\end{array}$ & $\begin{array}{l}\text { Provides } \\
\text { overview of } \\
\text { functional } \\
\text { status. } \\
\text { Evaluating } \\
\text { care plan } \\
\text { progress. }\end{array}$ \\
\hline $\begin{array}{l}\text { Sedentar } \\
\mathrm{y}\end{array}$ & $\begin{array}{l}\text { Proximity } \\
\text { to a single } \\
\text { area for } \\
\text { period }\end{array}$ & $\begin{array}{l}\text { Range and } \\
\text { HR from } \\
\text { BLE device } \\
\text { stays } \\
\text { consistent. }\end{array}$ & $\begin{array}{l}\text { Evaluating } \\
\text { care plan } \\
\text { progress. } \\
\text { Physical } \\
\text { capability } \\
\text { assessment }\end{array}$ \\
\hline Fall & $\begin{array}{l}\text { Motion to } \\
\text { Sedentary } \\
\text { with force } \\
\text { detection }\end{array}$ & $\begin{array}{l}\text { Force } \\
\text { detection, } \\
\text { increase in } \\
\text { HR, range } \\
\text { from BLE } \\
\text { device is } \\
\text { static from } \\
\text { motion } \\
\text { event }\end{array}$ & $\begin{array}{l}\text { Real time / } \\
\text { Historical } \\
\text { falls. } \\
\text { Independence } \\
\text {. Physical } \\
\text { safety }\end{array}$ \\
\hline
\end{tabular}

Source: George et al, 2004, Katz, 1983

Events are examined for during experiments using identification metrics as described in table 1, whilst accuracy of identification is verified by examining events against known activities undertaken by the subject during experiments. RA is not performed on a patient subjects to verify accuracy, rather events are captured as metrics of interest to RA frameworks with the goal of assisting the diminishing healthcare workforce. 


\section{Experiments}

Two sensor-observed experiments took place inside a single-story building, it contained several rooms with enough scope for the subject to perform the actions which will indicate the events to be examined. BLE devices are placed on a wall within three rooms, a chair and on a bed.

\subsection{Settings, Environment and Technical Metrics}

Devices receiving BLE signals, which are located on the subject include an Android smartphone and Motorola smartwatch. BLE devices used to send signals included Estimote Bluetooth Low-Energy Beacons using the Eddystone application programing interface. Proximity of the subject is recorded using received signal strength indication (RSSI) which has acceptable accuracy when determining location and interactions with BLE devices (Power et al, 2018). Fall events were performed using a crash mat while sedentary events used a chair. Experiments take place within a single-story building with a variety of rooms including a bathroom, bedroom, living room, kitchen and office which simulate a patient's home environment as shown in figure 1 .

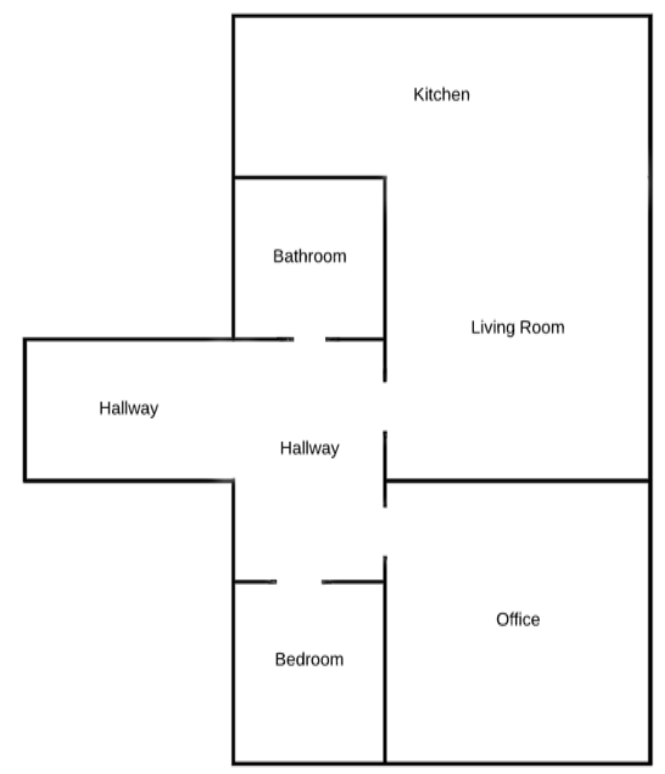

Fig. 1. Experimentation Environment
BLE beacons are placed in rooms by their function which identifies with a RA condition, with living rooms and bedrooms implying sedentary activity while kitchens indicate nourishment attempts and movement between these rooms determining movement transfer.

\subsection{Equipment}

BLE Receivers including a non-wearable iPhone 7 (IOS, 10.2) and a wearable Sony Smartwatch 3 (Android Wear, 1.5) were used in experiments. BLE devices used to send signals included Estimote Bluetooth LowEnergy Beacons (Eddystone and iBeacon frameworks). The BLE beacons required no specific software while the receiver devices used custom built applications created in JavaScript and Swift respectively.

These applications used BLE application programming interfaces (Eddystone, iBeacon) to record variables transmitted by the beacon advertisers. Estimotes brand of BLE beacons include a protective plastic housing, a circuit board featuring a Bluetooth chip, a temperature reader and a force meter powered by a CR2477, 3V Lithium battery with a capacity of 1000 milliamp hours (mhA) rated up to 2 years of standard use. There is no capacity to store data on BLE beacons used. All device interceptions of BLE signals were recorded on the capture devices applications and stored as csv files.

\subsection{Event Identification}

In this experiment the subject performed several activities in the environment which would indicate an event. At set time intervals walking, sitting and falling would be performed.

Table 2 shows all events performed during experiments and how many times these were recorded accurately. Incorporating HR detection and an accelerometer in BLE monitoring provides additional validation of any given event. Table 3 shows an example of a set of events identified over a one-hour period, correct reporting matches the observed event with the actual event. 
4 Luke Power, Sarah Dunnett and Lisa Jackson

Table 2: Event Monitoring Accuracy Across All Tests (85)

\begin{tabular}{lcc}
\hline Event & $\begin{array}{c}\text { Total (Events } \\
\text { Identified) }\end{array}$ & $\begin{array}{c}\text { Recorded } \\
\text { Correctly (\%) }\end{array}$ \\
\hline Motion & 57 & $94 \%$ \\
Sedentary & 18 & $97 \%$ \\
Fall & 10 & $100 \%$ \\
\hline $\begin{array}{l}\text { Source: Total of 10 experiments which observed } \\
\text { for RA events and their rate of accuracy using } \\
\text { descriptions outlined in table 1 }\end{array}$
\end{tabular}

As the subject performed scripted actions the data was examined for changes in RSSI, fluctuation of accelerometer and gyroscope and the elevation of HR. The experiment began with a transition from motion to a sedentary position, motion could be observed due to the fluctuation of RSSI between BLE stationary devices placed around the home as well as the motion sensors on the BLE wrist band showing significant increases in pitch indicated swinging arm motion for walking (Ao, B et al, 2018).

Table 3: Event Identification Example - T018 - 17:00 to 18:00

\begin{tabular}{|c|c|c|c|c|}
\hline $\begin{array}{l}\text { Timest } \\
\text { amp }\end{array}$ & $\begin{array}{l}\text { Event } \\
\text { Identifi } \\
\text { ed }\end{array}$ & $\begin{array}{l}\text { Heart Rate } \\
(B P M)(A \\
\text { VG) }\end{array}$ & $\begin{array}{l}\text { Motion } \\
\text { Sensor }\end{array}$ & $\begin{array}{l}\text { Descripti } \\
\text { on }\end{array}$ \\
\hline $\begin{array}{l}17: 00 \\
- \\
17: 02\end{array}$ & Motion & $72 \mathrm{BMP}$ & Walking & $\begin{array}{l}\text { Fluctuati } \\
\text { ng RSSI, } \\
\text { consiste } \\
\text { nt } \\
\text { accelero } \\
\text { meter } \\
\text { pitch, } \\
\text { heighten } \\
\text { ed HR }\end{array}$ \\
\hline $\begin{array}{l}17: 02 \\
- \\
17: 30\end{array}$ & $\begin{array}{l}\text { Sedent } \\
\text { ary }\end{array}$ & $57 \mathrm{BMP}$ & $\begin{array}{l}\text { Minor } \\
\text { pitch, } \\
\text { consisten } \\
\text { tly minor } \\
\mathrm{x}, \mathrm{y}, \mathrm{z} \\
\text { axial } \\
\text { fluctuati } \\
\text { ons }\end{array}$ & $\begin{array}{l}\text { Resting } \\
\text { HR, no } \\
\text { sudden } \\
\text { pitch } \\
\text { change, } \\
\text { RSSI } \\
\text { consiste } \\
\text { nt }\end{array}$ \\
\hline
\end{tabular}

\begin{tabular}{|c|c|c|c|c|}
\hline $\begin{array}{l}17: 30- \\
17: 45\end{array}$ & Motion & 74 BMP & Walking & $\begin{array}{l}\text { Fluctuati } \\
\text { ng RSSI, } \\
\text { consiste } \\
\text { nt } \\
\text { accelero } \\
\text { meter } \\
\text { pitch, } \\
\text { heighten } \\
\text { ed HR }\end{array}$ \\
\hline $17: 45$ & Fall & 73 BMP & Fall & $\begin{array}{l}\text { Sudden } \\
\text { accelerat } \\
\text { ion on y } \\
\text { axis }\end{array}$ \\
\hline $\begin{array}{c}17: 45 \\
- \\
18: 00\end{array}$ & Fall & $60 \mathrm{BMP}$ & $\begin{array}{c}\text { Inconseq } \\
\text { uential } \\
\text { pitch } \\
\text { moveme } \\
\text { nts }\end{array}$ & $\begin{array}{l}\text { Consiste } \\
\text { nt RSSI } \\
\text { location, } \\
\text { no force } \\
\text { or } \\
\text { motion } \\
\text { detected }\end{array}$ \\
\hline
\end{tabular}

Although HR appears to also be elevated it is difficult to say this indicates movements for certain as there is no historical data available on this subject while they are walking. The following event which was sedentary behaviour did however show an expected drop in HR while lack of acceleration and consistent RSSI between BLE emitter devices placed the subject in one location for the stated time of 17:02 to 17:30. The subject then begins motion for 15 minutes which is observed with an increase in HR, the return to a similar pitch pattern from the motion detection and fluctuating RSSI which does seem to indicate a motion pattern for this subject.

Following the motion is a fall event, the primary identification of the fall event is the sudden acceleration observed on the yaw axial of the accelerometer and gyroscope which indicates a shift downward while the return to normality on the sensor indicates the event has ceased (Mao et al, 2017). The fall can be validated through the sedentary behaviour following the event as the subject now exhibits signs of the behaviour with a constant RSSI from BLE devices with no force or motion applied to the wrist worn BLE receiver. Although falls may be proceeded by the subject recovering their position the event alone could be recorded while RSSI confirmed sedentary actions thereafter. 


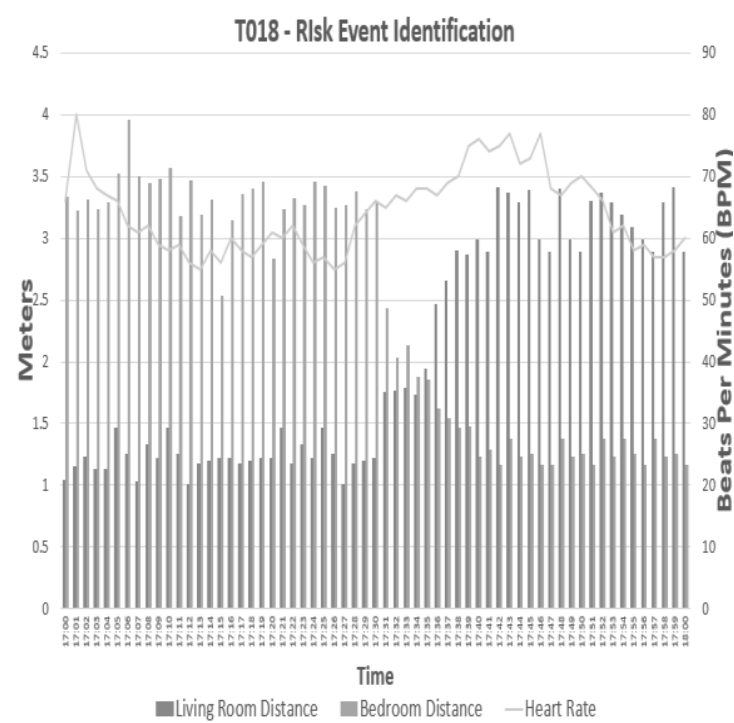

Fig. 2. Visual Overlay of T018 Risk Event Identification

Figure 2 shows each data point captured during the experiment. During the first motion event there is a peak in heart awhile location between the living room and bedroom remains at similar levels indicating movement without transferring between environments. Following this is a sedentary period of stable heart rate and location without a motion flag.

The transfer event is then observed from 17:30 to 17:45 with an elevated heart rate and a decrease in distance recorded between the bedroom BLE device and the Living room device - this indicates a transfer event between these locations with heart rate indicating movement. At 17:45 there is a fall event which doesn't show a difference in location in between the room devices but heart rate does initially increase dramatically before stabilizing into a sedentary period.

The events observed in this experiment and in the additional experiments described for this paper shows efficacy in BLE sensors hosting a platform of devices such as the heart rate and motion sensors which can identify activities which relate to RA factors.

\section{Discussion}

This paper examined BLE device suitability for RA in elderly homecare, three patient activity events were monitored including movement, sedentary behaviour and falls. Two experiments focused on occupant monitoring which demonstrated an ability to record RA events accurately, $97 \%$ of events in the event experiment were classified correctly. Using RSSI between BLE devices and validating with HR and motion sensors, activities necessary to determine patient risk were determined with a high degree of accuracy.

These events could be determined using the identification criteria due to the combination sensors made possible on the BLE platform with a high degree of accuracy for individual event types. Pattern of events and activities could potentially be established through long term analysis of events like these observed. There is also the possibility to include historical analysis of movement, motion characteristics, falls and HR to determine deterioration or indeed improvement of patient RA outcomes. This will be explored in future work.

\subsection{Impact on Risk Assessment}

Provision of RA in homecare is a resource heavy activity which is a significant issue in the continuing ability for health care providers to maintain quality care in the home.

BLE implemented on a device has demonstrated feasibility in providing remote observations which RA frameworks require to estimate patient risk factors. Implementing this technology for specific care requirements with individualized events to monitor could being to resolve the issue of resource heavy RA provision. Using BLE, it is also possible to incorporate additional devices currently used for RA in homecare such as the motion and fall sensor. As BLE is a ubiquitous signal standard, additional medical devices may also be incorporated for homecare activity monitoring beyond RA such as diabetes monitors.

\subsection{Future Work}

This preliminary study into BLE devices for RA included limitations such as the lack of experiments conducted within multi-storey buildings which could pose additional challenges for pattern recognition and overall accuracy of event identification. Distances may also be inaccurate when using devices advertising from different floors in calculations as they must travel through the height of the room. 
Although efforts have been made to utilize as many observations as possible the experiments were limited to three event types which does not cover all aspects of potentials risks a patient may encounter. Event identification also has the potential to be more accurate as descriptions of these events are only interpreted from relevant RA literature.

Heart rates also fluctuate between individuals making it unreliable as a metric by itself. Future work will seek to incorporate care professionals' input to obtain more accurate classifications and thus more accurate observations. Pattern analyses may also be developed into algorithms controlled by artificial intelligence to adapt to changes in patient behaviour and develop custom events to be observed, this would be the next step following this paper which demonstrated the ability to identify patterns.

\section{Conclusion}

RA is vital to deliver effective care plans for elderly patients with the primary barrier to providing effect assessments being the lack of available health professionals to carry out the necessary observations.

Additional methods to obtain RA using captured data could potentially inform an FMEA analysis to provide a more accurate reflection of risk however as there are limitations with currently researched device the focus of this work was on obtain RA data which is relevant to the area of homecare. Currently employed devices which seek to meditate the limitations with current RA technologies in the home such as the occupancy sensor and the video camera. BLE devices address both these issues, in experiments BLE devices could accurately classify the limited set of events considered. While accuracy could be established to determine events, $100 \%$ accuracy was unachievable due to the BLE signal standard which emits a low powered radio signal, highly influenceable by interference. Using additional devices improves the accuracy of risk factor visibility, indicating that technology like this could be employed to identify more patient specific events with absolute accuracy as part of a complete automated remote monitoring platform which requires less workforce to utilize than currently employed.
As mentioned, by incorporating the heart monitor and gyroscope made it possible to validate events using a single device. This paper has demonstrated the suitability of BLE devices to enabled RA assessment in the home environment through establishing consistent event identification and establishing patterns of behaviour. 


\section{References}

Allard, M., Husky, M., Catheline, G., Pelletier, A., Dilharreguy, B., Amieva, H., Pérès, K., Foubert-Samier, A., Dartigues, J.-F. and Swendsen, J. (2014) 'Mobile technologies in the early detection of cognitive decline', PLoS ONE, 9(12), p. e112197

Attia, M., Moussa, A. and El-Sheimy, N. (2013). Map Aided Pedestrian Dead Reckoning Using Buildings Information for Indoor Navigation Applications. Positioning, 04(03), pp.227239.

Ao, B., Wang, Y., Liu, H., Li, D., Song, L. and Li, J. (2018). Context Impacts in AccelerometerBased Walk Detection and Step Counting. Sensors, 18(11), p.3604.Author, F. and S. Author (2015). Article title. Journal Title 10, 20-30

Baker, S. and Quatier, B. (2011). Remote Patient Monitoring. US 20140331298

Barlow, J., Singh, D., Bayer, S. and Curry, R. (2007) 'A systematic review of the benefits of home telecare for frail elderly people and those with long-term conditions', Journal of Telemedicine and Telecare, 13(4), pp. 172179.

Caradoc-Davies, T., Dixon, G. and Campbell, A. (1989). Benefit from Admission to a Geriatric Assessment and Rehabilitation Unit. Journal of the American Geriatrics Society, 37(1), pp.25-28.

CarersUK (2015) Https://www.Carersuk.Org/forprofessionals/policy/policy-library/factsabout-carers-2015).

George A. Zsidisin, Lisa M. Ellram, Joseph R. Carter, Joseph L. Cavinato, (2004) "An analysis of supply risk assessment techniques", International Journal of Physical Distribution \& Logistics Management, Vol. 34 Issue: 5, pp.397-413, https://doi.org/10.1108/09600030410545445

Hesselink, G., Schoonhoven, L., Plas, M., Wollersheim, H. and Vernooij-Dassen, M. (2012). Quality and safety of hospital discharge: a study on experiences and perceptions of patients, relatives and care providers. International Journal for Quality in Health Care, 25(1), pp.66-74.

Mao, A., Ma, X., He, Y. and Luo, J. (2017). Highly Portable, Sensor-Based System for Human Fall Monitoring. Sensors, 17(9), p.2096.

Soldato, M., Liperoti, R., Landi, F., Finne-Sovery, H., Carpenter, I., Fialova, D., Bernabei, R. and Onder, G. (2007). Nonmalignant daily pain and risk of disability among older adults in home care in Europe. Pain, 129(3), pp.304-310.

Vegesna, A., Tran, M., Angelaccio, M. and Arcona, S. (2017) 'Remote patient monitoring via non-invasive digital technologies: A systematic review', Telemedicine and e-Health, 23(1), pp. 3-17. doi: 10.1089/tmj.2016.0051.

Wade, V., Karnon, J., Eliott, J. and Hiller, J. (2012). Home Videophones Improve Direct Observation in Tuberculosis Treatment: A Mixed Methods Evaluation. PLoS ONE, 7(11), p.e50155. 